\title{
Evaluation of Ischaemia Modified Albumin as a Marker of Oxidative Stress in Beta Thalassemia Major Children
}

\section{K Jagadish Kumar' ${ }^{1}$,Smriti Bhagiratha ${ }^{1}$ and Prashanth Vishwanath ${ }^{2}$}

${ }^{1}$ Department of Paediatrics, JSS Medical College, JSS Academy Of Higher Education And Research., Mysore, India

${ }^{2}$ Department of Biochemistry, JSS Medical College, JSS Academy Of Higher Education And Research, Mysore, India

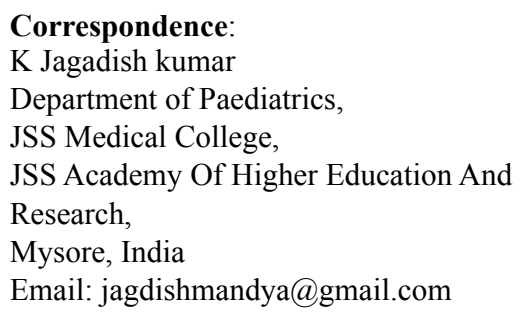

Email: jagdishmandya@gmail.com

DOI: $10.3126 /$ jnps.v41i1.29931

Submitted on: 2020-07-09

Accepted on: 2020-02-18

\section{Acknowledgements: None}

Funding: Nil

Conflict of Interest: None declared

Permission from IRB: Yes
To cite this article: kumar $\mathrm{KJ}$, Bhagiratha S, Vishwanath V. Evaluation of Ischaemia Modified Albumin as a Marker of Oxidative Stress in Beta Thalassemia Major Children. J Nepal Paediatr Soc. 2021;41(1):61-6.

\section{ABSTRACT}

Introduction: Iron overload in thalassemia catalyses the production of a variety of reactive oxygen species leading to cumulative cell damage. Ischemia modified albumin (IMA) is an end product of oxidative stress. It is imperative to pick up oxidative stress early in order to prevent the organ damage in thalassemia. Therefore this study was undertaken to estimate IMA levels and to see the correlation between ferritin and IMA to establish whether ferritin can be a proxy marker for oxidative stress.

Methods: A total of 76 children were included in the study out of which 46 were diagnosed cases of $\beta$ - Thalassemia major and 30 formed the healthy controls. Pre transfusion haemoglobin, AST, ALT, ferritin and IMA levels were estimated and compared with healthy control children. Correlation was drawn between haemoglobin, AST, ALT, ferritin with IMA.

Results: There is significant elevation in the level of IMA and ferritin in children with Thalassemia major as compared to the healthy controls $(\mathrm{p}=<0.001)$. There was a significant positive correlation between ferritin and IMA and a significant negative correlation between haemoglobin \% and IMA. Regression relationship between ferritin and IMA established that IMA (ng/ $\mathrm{mL})=246.118+0.829($ Ferritin $\mathrm{ng} / \mathrm{dL})$.

Conclusions: IMA levels were significantly elevated in $\beta$ thalassemia major children and correlated positively with ferritin levels. By establishing a regression relationship between ferritin and IMA levels, we can fairly estimate the levels of IMA. Hence, we can utilise ferritin as a proxy marker of oxidative stress instead of IMA.

Keywords: $\beta$-thalassemia major; Ferritin; Ischemia modified albumin (IMA); Oxidative stress

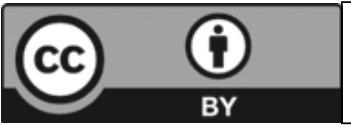

This work is licensed under creative common attribution 3.0 license 


\section{INTRODUCTION}

Beta thalassemia syndromes are a group of haemoglobinopathies caused due to decreased production of beta globin chains. Throughout the world, there are 270 million carriers with abnormal haemoglobins and thalassemias, of which 80 million are carriers of $\beta$-thalassemia. Every year, around 300,000 to 400,000 babies are born with a serious haemoglobin disorder of which 23,000 are born with $\beta$-thalassemia major and majority $(90 \%)$ of them born in low or middle income countries. ${ }^{1,2}$ Every year 50,000 to 100,000 deaths occur due to severe beta thalassemia and accounts for $0.5 \%$ to $0.9 \%$ of all deaths of children under five years of age in low or middle income countries. $^{2}$ Majority of thalassemia affects people of Mediterranean populations, in the Middle East, in parts of Indian subcontinent and South East Asia. ${ }^{2}$ It is estimated that the prevalence of $\beta$ thalassemia in India is $3 \%-4 \%$ with about 8000-10,000 children being born every year with major disease. ${ }^{3}$ Regular transfusion therapy and iron chelation has improved the survival and quality of life. Iron overload in thalassemia is caused by increased dietary iron absorption and repeated blood transfusions. This in turn leads to increase in redox active fractions such as nontransferrin-bound iron (NTBI) and labile plasma iron (LPI) in the circulation. ${ }^{4,5}$ Excessive iron catalyses the production of a variety of reactive oxygen species (ROS), leading to cumulative cell damage., ${ }^{4,5}$ Generation of ROS can modify the Nterminal region of albumin and produce an increase in IMA levels. Albumin in which the N-terminus is either damaged or occupied by copper is termed as IMA. ${ }^{4}$ Recently, it was found that IMA is an end product of oxidative stress. ${ }^{5}$ Elevated levels of IMA may reflect a generalised rather than organ specific state of oxidative stress. ${ }^{5}$ It has also been demonstrated that thalassemia patients experience decreased antioxidant capacity. ${ }^{4}$ Therefore, effective iron chelators are required to remove the toxic irons to prevent oxidative damage in the vital organs. ${ }^{5}$ IMA utility has been studied in various conditions like stroke, acute coronary syndrome and hypoxic ischaemic encephalopathy (HIE) in neonates. ${ }^{6-8}$ IMA levels might increase in patients with end-stage renal disease, skeletal muscle ischemia, pulmonary embolism, acute mesenteric ischemia and intrauterine ischemia. ${ }^{6}$ In complicated pregnancies cord blood IMA levels could be used as a marker for foetal ischemia. ${ }^{6}$ It is imperative to pick up oxidative stress early in order to prevent the organ damage. Various studies have demonstrated significantly higher level of IMA in the children with $\beta$-Thalassemia compared to healthy controls. ${ }^{4,5,9-11}$ Currently known marker to assess iron overload is serum ferritin which is quite reliable and economically feasible. Awadallah et al. concluded that ferritin was found to be the predictor of the IMA status in TM. ${ }^{4}$ We wanted to know the correlation between ferritin and IMA levels in beta thalassemia children and whether ferritin levels can be used as a marker of oxidative stress instead of IMA. Even though India being a hot bed there is very scarce literature/data documenting oxidative stress markers in thalassemia in our subcontinent. Therefore this study was undertaken to establish the role of IMA in thalassemia major children and to evaluate its correlation with levels of serum ferritin.

\section{METHODS}

This hospital based prospective cross sectional study was conducted in the Department of Paediatrics in JSS Hospital Mysuru, India during a period of 18 months from October 2017 to March 2019. Sample size was calculated based on prevalence of $\beta$-Thalassemia as $3.3 \%^{3}$ using Rao soft sample calculator http://www.raosoft.com/ samplesize.html. We have taken margin of error assumed to be $5 \%$ and confidence level as $90 \%$. Sample size was calculated as 35 cases. Children below 18 years of age diagnosed as $\beta$-Thalassemia major formed the study group. Children without $\beta$ Thalassemia major matched for age and sex formed the healthy control group. Children with history of fever in the last one week, symptomatic heart disease, hypothyroidism, diabetes mellitus and renal disease were excluded. Study was approved by JSS University Ethical Committee, Mysore (Reference No JSS/MC/PG/ 1018/ 2018-19, Dated 22 may 2018) and written consent was taken from the study group parents and healthy controls. Detailed history and clinical examination was carried out with specific importance to blood transfusions, chelation and complications. 
Transfusion index was calculated retrospectively for last two years. Transfusion index $=$ Volume of transfused packed red cells in $\mathrm{mL}$ per $\mathrm{kg}$ body weight per year (mean value of last two years). Prior to transfusion venous blood was collected for estimation of Haemoglobin, AST, ALT, Ferritin and IMA levels. Haemoglobin was estimated by SYSMEX 6 part haematology analyser, ALT, AST, ferritin by COBAS 6000 and E501 analyser. IMA estimated by ELISA by the Human Ischaemia Modified Albumin ELISA kit supplied by Sincere Biotech Co., Ltd. China. Statistical analyses were done using SPSS 21.0 version for windows by means of proportions for categorical / binary variables and mean, median, standard deviation, inter quartile range (IQR) for continuous variables. Pearson correlation was used to correlate the two continuous variables which are normally distributed.

\section{RESULTS}

The study included 76 children out of which 46 were $\beta$-Thalassemia major (TM group) and 30 age and sex matched healthy controls (HC group). Demographic pattern of both groups are depicted in

Table 1. Demographic and Laboratory data among TM and HC groups

\begin{tabular}{|c|c|c|c|}
\hline Parameter & $\begin{array}{l}\text { Healthy } \\
\text { Controls } \\
(\mathrm{HC}) \\
(\mathbf{n}=\mathbf{3 0})\end{array}$ & $\begin{array}{l}\text { Thalassemia } \\
\text { Major (TM) } \\
(\mathrm{n}=46)\end{array}$ & p value \\
\hline Males & 18 & 30 & 0.6 \\
\hline Females & 12 & 16 & 0.6 \\
\hline $\begin{array}{l}\text { Median age in } \\
\text { years }\end{array}$ & 9 & 9.5 & \\
\hline $\begin{array}{l}\text { Weight } 3 \text { rd to } \\
25 \text { th centiles }\end{array}$ & $56.6 \%$ & $71.8 \%$ & 0.03 \\
\hline $\begin{array}{l}\text { Height } 3 \text { rd to } \\
25 \text { th centiles }\end{array}$ & $53.2 \%$ & $60.9 \%$ & 0.03 \\
\hline $\begin{array}{l}\text { Mean } \\
\text { Haemoglobin in } \\
\mathrm{g} / \mathrm{dL}\end{array}$ & 12.97 & 8.5 & $<0.00011$ \\
\hline AST (U/mL ) & 26.06 & 54.62 & $<0.00011$ \\
\hline ALT (U/mL ) & 15.06 & 41.29 & $<0.00011$ \\
\hline Ferritin $(\mathrm{ng} / \mathrm{mL})$ & 19.05 & 1430.33 & $<0.00011$ \\
\hline IMA ( ng/mL) & 377.19 & 1399.57 & $<0.00011$ \\
\hline
\end{tabular}

the table 1. The median age of subjects in healthy children group is nine years and in thalassemia major group, is 9.5 years. There was no statistically significant difference between the two groups [Table 1]. In TM children the mean duration since diagnosis was 8.25 years [range 3.9 to 12.5 years]. The average transfusion index computed over last two years was $176 \mathrm{~mL} / \mathrm{kg} /$ year in TM group. Among the TM children (46), 38 were on Deferasirox, six were on both Deferasirox and Deferiprone and two were not on any iron chelators. The mean haemoglobin among the thalassemia major children was $8.5 \mathrm{gm} / \mathrm{dL}$ and among the healthy children was $12.97 \mathrm{gm} / \mathrm{dL}$. IMA and ferritin levels were significantly high in TM group when compared to healthy controls [Table 1]. In TM group, IMA had negative correlation with haemoglobin and this was statistically significant $(\mathrm{p}$ $=0.008, \mathrm{r}=-0.678)$ [Graph 1]. IMA has significant positive correlation with AST $(\mathrm{p}=<0.0001, \mathrm{r}=$ $0.681)$ and ALT $(p=<0.0001, r=0.523)$ in TM group. Graph 2 shows that IMA has a positive correlation with ferritin $(\mathrm{p}=<0.001, \mathrm{r}=0.749)$ in TM group and it was found to be statistically significant. Regression relationship between Ferritin levels and IMA levels was done [Graph 3]. The aim was to assess how the value of IMA changed with variation in ferritin. Regression relationship between ferritin levels and IMA levels is IMA $(\mathrm{ng} / \mathrm{mL})=246.118+0.829$ ferritin $(\mathrm{ng} / \mathrm{dL})$.

\section{DISCUSSION}

In thalassemia, iron overload results in increased levels of redox active fractions such as NTBI and

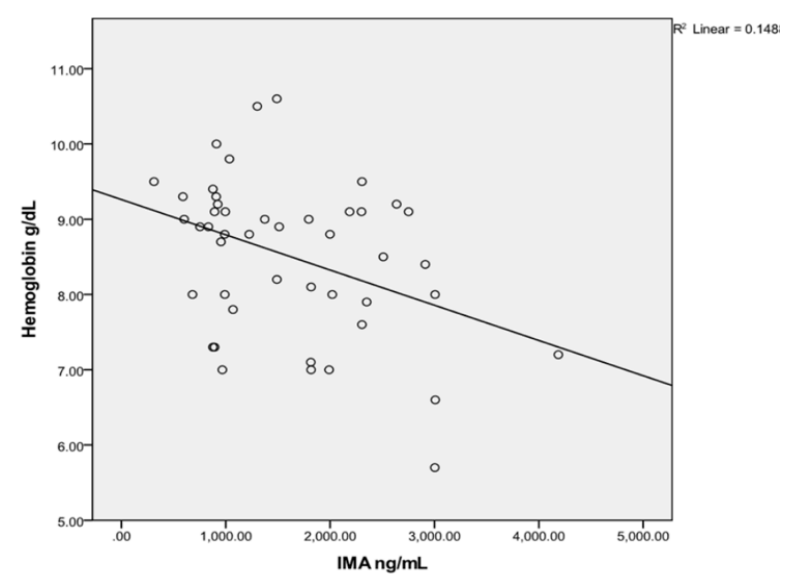

Figure 1. Correlation between IMA and Haemoglobin 


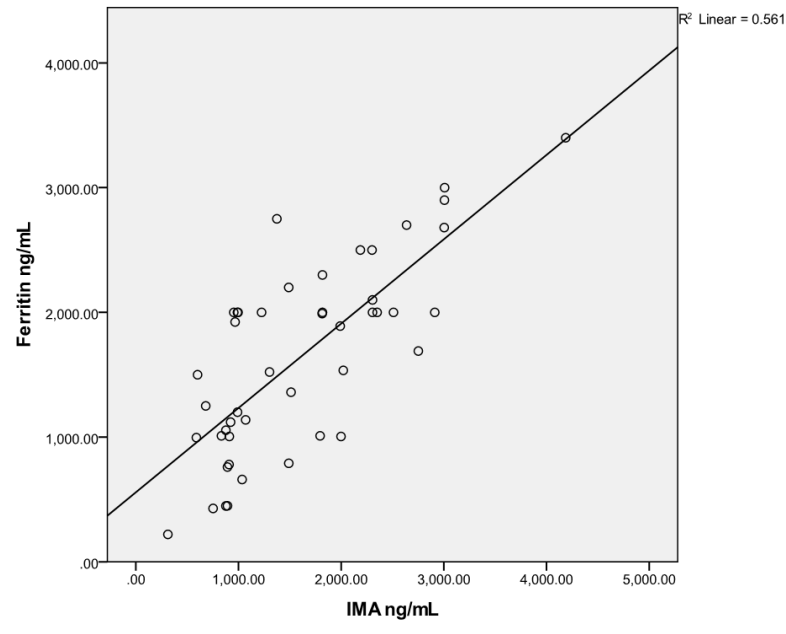

Figure 2. Correlation between IMA and Ferritin

LPI. These fractions catalyse the production of ROS and plays a major role in the formation of IMA. ${ }^{4,5}$ IMA utility has been studied in various conditions. Dursun et al. observed elevated levels of IMA among neonates with HIE when compared with normal babies. ${ }^{6}$ Sinha et al. demonstrated that IMA was not only a sensitive marker of cardiac ischaemia but also showed early response to cardiac injury which is not picked up by other routine diagnostic tests. ${ }^{7}$ Abboud et al. showed IMA to be a possible biomarker in patients with stroke. ${ }^{8}$ Various studies have demonstrated significantly higher level of IMA in the children with $\beta$-Thalassemia compared to healthy controls. $4,5,9,10$ This indicates that the level of oxidative stress is higher among children with thalassemia major. Few studies revealed that children on deferiprone and deferasirox had significantly lower IMA levels compared with children not on chelators. 5,9 This can be due to a decrease in the circulating and intracellular free iron that leads to a decrease in the formation of ROS in children on oral chelators. ${ }^{5}$ However all our children were on oral chelators except two. Therefore, effective iron chelators are required to remove the toxic irons to prevent oxidative damage in the vital organs.

We recorded high mean ferritin values among TM children when compared to controls. Similar finding has been noted in various studies. ${ }^{4,5,9,10} \mathrm{We}$ observed significant difference in the liver enzymes levels (AST, ALT) between TM and HC group which can be due to the liver injury occurring consequent to iron overload. Similar observations
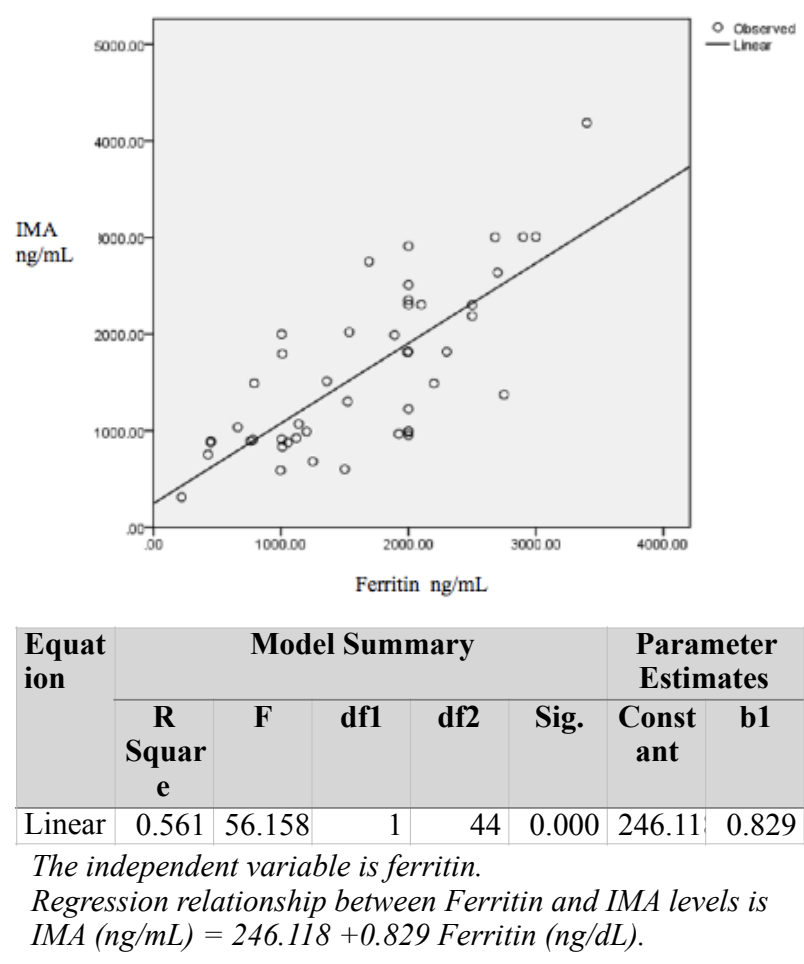

Figure 3. Regression relationship between IMA and Ferritin

has been made by other workers. ${ }^{5}$ We observed a strong and statistically significant positive correlation between serum ferritin and IMA levels which is a consistent finding in other studies also. $4,5,9,10$ Study from Egypt revealed that when serum ferritin is equal to $2500 \mathrm{ng} / \mathrm{ml}$, IMA has a cut off value greater than $107 \mathrm{ng} / \mathrm{ml}$ with a sensitivity of $68.9 \%$ and a specificity of $48.3 \%{ }^{5}$ Adlly et al. found significantly higher IMA levels among $\beta$-thalassemia patients with heart disease. They observed that the cut off value of IMA at 17.5 $\mathrm{U} / \mathrm{ml}$ could differentiate heart disease in $\beta$ thalassemia patients with sensitivity of $80.5 \%$, specificity of $88.9 \%$ and positive predictive value of $96.7 \%$ and negative predictive value of $73.3 \% .{ }^{9}$ They noted that IMA levels correlated positively with tricuspid regurgitant jet velocity (TRV) and negatively with both ejection fraction and fractional shortening. They also demonstrated a positive correlation between carotid intima media thickness (CIMT) and IMA and suggested that IMA can be used as a marker of subclinical atherosclerosis in $\beta$ thalassemia patients. ${ }^{9}$ However Odaman et al. found weak positive correlations between serum ferritin and IMA. ${ }^{11}$ Awadallah et al. observed significantly lower levels of total antioxidant 
capacity (TAC) in TM than in controls. They demonstrated significant inverse correlations of TAC with both IMA and ferritin. They concluded that IMA should be included as one of the oxidative stress markers in thalassemic patients. ${ }^{12}$ Elbeblawy et al. showed that IMA has positive correlation with cardiac dimensions as LVIDD and LVIDS while there was negative correlation with EF and FS. IMA of $190 \mathrm{ng} / \mathrm{ml}$ was the cut off value between normal and abnormal values of LVIDD, LVIDS, EF and FS. They opined that increased levels of IMA in TM patients varies significantly with impaired cardiac systolic dysfunction. ${ }^{10}$ Studies including the current one, have established that IMA is a reliable marker of oxidative stress and have even explored the possibility of its utility as an early marker before irreversible damage has occurred. Though IMA is a very accurate marker its utility is not practical because of economic constraints. Whereas ferritin estimation is economically feasible. Awadallah et al. concluded that ferritin was found to be the predictor of the IMA status in TM. ${ }^{4}$ In our study we could also predict the IMA status in children with $\beta$-thalassemia major. What is novel in our study is that we have also devised a regression relationship between ferritin and IMA levels thereby we can fairly estimate the levels of IMA by using, IMA $(\mathrm{ng} / \mathrm{mL})=246.118+0.829$ (Ferritin $\mathrm{ng} / \mathrm{dL}$ ). Hence, we can utilise ferritin as a proxy marker of oxidative stress instead of IMA. By introducing a simple and economically feasible biochemical parameter such as ferritin to estimate not only the level of iron overload, but also for the level of oxidative stress, early detection can be ensured before organ damage. Further studies are warranted to establish the standardised level at which IMA and ferritin can signify clinically damaging oxidative stress. It is vital to recognise this early to prevent irreversible damage to different organs.

Our study does have few limitations. It is a single centric study and hence, the findings may not be applicable to the entire Indian population. We could not also find the standardised value of IMA which could specifically demarcate clinically significant oxidative stress. Despite these limitations, we are hopeful that our findings would propel further larger, multi centric studies upon this subject in the future.

\section{CONCLUSIONS}

There is significant elevation of IMA levels in $\beta$ thalassemia major children and IMA levels correlate positively with level of AST, ALT and ferritin. We devised a regression relationship between ferritin and IMA levels by which we can fairly estimate the levels of IMA. Hence, we can utilise ferritin as a proxy marker of oxidative stress instead of IMA.

\section{REFERENCES}

1. Abolghasemi H, Amid A, Zeinali S, Radfar MH, Eshghi P, Rahiminejad MS, et al. Thalassemia in Iran: epidemiology, prevention, and management. J Pediatr Hematol Oncol. 2007;29:233-8. DOI: 10.1097/MPH. $0 \mathrm{~b} 013 \mathrm{e} 3180437 \mathrm{e} 02$.

2. De Sanctis V, Kattamis C, Canatan D, Soliman AT, Elsedfy H, Karimi M, et al. $\beta$-Thalassemia Distribution in the Old World: an Ancient Disease Seen from a Historical Standpoint. Mediterr J Hematol Infect Dis. 2017;20:9(1):e2017018. DOI: 10.4084/MJHID.2017.018.

3. Mohanty D, Colah RB, Gorakshakar AC, Patel R Z, Master D C, Mahanta J, et al. Prevalence of $\beta$-thalassemia and other haemoglobinopathies in six cities in India: a multicentre study. J Community Genet. 2013;4(1):33-42. DOI: 10.1007/s12687-012-0114-0

4. Awadallah S, Atoum M, Nimer N, Saleh S. Ischemia modified albumin: an oxidative stress marker in $\beta$-thalassemia major. Clin Chim Acta. 2012;10:1016-37. DOI: 10.1016/j.cca.2012.01.037.

5. Omar Mousa S M, Afifi M F, Saedii A A, El-Setohy A A. Ischemia modified albumin in children with transfusiondependent $\beta$-thalassemia: a new marker for an old problem. Egypt J Haematol. 2016;41:45-9. DOI: $10.4103 / 1110-1067.186397$

6. Dursun A, Okumus N, Zenciroglu A. Ischemia-modified albumin (IMA): could it be useful to predict perinatal asphyxia? J MaternFetal Neonatal Med. 2012;25:2401-5. DOI: 10.3109/14767058.2012.697943. 
7. Sinha MK, Roy D, Gaze DC, Collinson PO, Kaski JC. Role of ischemia modified albumin a new biochemical marker of myocardial ischemia, in the early diagnosis of acute coronary syndromes. Emerg Med J. 2004;21:29-34. DOI: $10.1136 / \mathrm{emj} .2003 .006007$.

8. Abboud H, Labreuche J, Meseguer E, Lavallee PC, Simon O, Olivot JM, et al. Ischemia-modified albumin in acute stroke. Cerebrovasc Dis. 2007;23:216-20. DOI: 10.1159/000097644.

9. Adly AAM, ElSherif NHK, Ismail EAR, Ibrahim YA, Niazi G, Elmetwally SH. Ischemia-modified albumin as a marker of vascular dysfunction and subclinical atherosclerosis in $\beta$-thalassemia major. Redox Rep. 2017;22:430-8. DOI: $10.1080 / 13510002.2017 .1301624$.

10. Elbeblawy N MS, Abdelmaksoud AA, Elguindy WM, Elshinawy D, Abdelwahed GR. Ischemia modified albumin in Egyptian patients with $\beta$-thalassemia major: relation to cardiac complications. QJM. 2018;111(1). DOI: https:// doi.org/10.1093/qjmed/hcy200.167

11. Odaman Al I, Ayçiçek A, Ersoy G, Bayram C, Neşelioğlu S, Erel Ö. Thiol Disulfide Homeostasis and Ischemiamodified Albumin Level in Children With Beta-Thalassemia. J Pediatr Hematol Oncol. 2019;41(7):463-6. DOI: 10.1097/MPH.0000000000001535.

12. Awadallah $\mathrm{S}, \mathrm{Al}$ Arrayed $\mathrm{K}$, Bahareth $\mathrm{E}$, Saeed $\mathrm{Z}$. Total antioxidant capacity and ischemia modified albumin in beta thalassemia. Clin Lab. 2013;59:687-91.DOI: 10.7754/clin.lab.2012.120907 